\title{
Discussion on the Correct Method of Using Breath in Singing*
}

\author{
Shanshan Jiang \\ Heihe University \\ Heihe, China 164300
}

\begin{abstract}
Singing is the most beautiful music, while the vibration of voice is inseparable from the using of breath, which plays a very important role in the singing skills of pronunciation, articulation, continuity and integrity of the whole song. When singing, the different pitch, volume and the tension of the sound require different speed and depth of the breath that puffs the vocal cord. Only when the breath is full and stable, the resonance can be full, the tone can be unified, the emotion can be delicate, and voice and sentiment can be rich. It is the lifeline of learning vocal music, because if we leave it, everything is of no use. It is so-called: "The art of singing is the art of breath", so vocalists at all times and in all over the world attach great importance to the breath of singing. In ancient times, there is "Good singer must first regulate the breath since sound is generated when breath moves, so breath is the basis for the sound."
\end{abstract}

Keywords—singing; using breath; method

\section{INTRODUCTION}

Singing and breathing is an extensive and abstruse science. In the Italian Bel Canto School, there is such a statement: "Breath is the basis and power of singing, so those who know how to breathe knows how to sing." In vocal music theory of ancient China, there is saying that "good singer must first regulate the breath" and "sound is generated when breath moves". Today, we emphasize that breath is the source of voice, the driving force of singing, and the life of singing. It not only is a profound understanding of the importance of breath, but also highlights the important role of breath in singing. The correct voice, good resonance and even emotional expression of songs are closely related with the breath. Therefore, only by mastering the most natural, the deepest, and the most correct breath in singing can we have material motivation of songs with abundant expressive and enter into the realm of singing art more freely to achieve the harmony of spirit and body, and the unity of the role image and sound image.

There are two kinds of breaths in singing working at the same time. One is the pushing force upward and outward, and the other is the holding force downward and backward. The two oppose and exist in the singing. Because of this counter force, breathing have fulcrum, breath can be used,

*Fund Project Source: Heilongjiang Philosophy and Social Sciences Research Project in 2016 "Scientific Training and Health Study of Voice"; Project Number: 16YSC03. and the sound can be full and resilient. Beginners often overdo it by making suppressed and mechanical, so they cannot get the desired effect and they will be stiff and uncomfortable. The right way to use breath is like a wheel rolling, which is full of vitality.

\section{The Method OF USING BREATH IN SiNGING}

In vocal music circle, there is such a motto: "Those who know how to breathe knows how to sing." Whether we can sing good songs, breathing is the key. Therefore, in order to make progress in singing study, we must first solve the problem of breathing. The establishment of a complete, scientific and systematic method of singing and breathing is a problem that the vocal music circle has been studying and exploring.

\section{A. The Use of Breath in Singing Should Be Deep, Steady Unblocked, and Lively}

"Deep" refers to using the breathing method combining chest, abdomen, and diaphragm to make pressure be maintained in the area of waist and belly so that the driving force of breath and keeping force form confrontation. "Steady" refers that breath should pursue balance and unify in the above confrontation and use the breath economically, to exhale in a controlled, steady and even way. Otherwise, if the exhaled volume suddenly becomes big or small or the flow velocity is too fast, the sound will come in and out, but not in a line, or breath is not enough. "Open" refers that the breath channel is unimpeded, so chest, neck, shoulders, chin, lower jaw, and maxillary joint, etc. should be relaxed and natural. The whole body should avoid any unnecessary tension, so as not to block the airflow and sound waves. Only by achieving "loose" can one achieve "open". The right inhalation can expand and clear the breath channel and exhaling need to maintain smooth, in order to give full play to the effect of the breath on the sound. "Live" means that the breath should be flexible and energetic. This is under the premise of "deep", "steady" and "unblocked", or the sound will be unstable, shallow, floating and scattered. It is useful for singers to first imagine a wheel spinning around after inhaling and before singing.

\section{B. The Voice and Breath in Singing Must Be Balanced}

When the pitch and volume change, the feeling of using breath is different. When the pitch rises, the breath should be 
deep and stable with a low supporting point by slightly increasing respiratory pressure. The two groups of muscle used in exhalation and Inhalation should actively work at the same time and waist muscles expand outward powerfully and flexibly to push the waist, so that the kind of feeling of "sitting" backward and downward on both sides of the back of waist is particularly evident. We can feel the sound and breath is anti-going, with the sound upward while breath down. The sound is high while breath is low, so the distance is pulled large. In this way, the breath is used both intensively and economically, and the sound can be rounded, erect, and penetrating. If with the rise of sound, the breath is also brought up, high pitch can't be made due to the lack of pressure caused by shallow breath. Even high pitch is made by desperately shouting or squeezing, the volume is not loud and the sound is not beautiful. Excessive power of breath is also wrong. On one hand, it affects the intonation; on the other hand, it can cause vocal cord lesions. When the pitch is low, the vocal cord is more relaxed and not tight. Since the glottis is not tightly closed, the role of blocking breath is not strong; part of breath will be missed. If the breath is low as the pitch is low, it will be too late to delivery, and the sound can't be resounding, but virtual and powerless, so the breath should be lift slightly, similar to the breath used in talking. At this moment, the counter force of bi-directional movement of breath still need to be maintained, and psoas, diaphragm, abdominal muscles, and two ribs cannot be nerveless, or the intonation will be low, the sound position cannot be maintained, and the sound emitted becomes transverse and scattered.

When the sound is weak, soft and warm, the breath should be balanced, slowly and moderately. Especially the weak sound in the high-pitched area must be controlled well to keep the breath flowing evenly and the waist should maintain the strong and tenacious feeling of pushing the waistband when singing strong voice. That is to say, waist should maintain the breath speed when making strong sounds. The difference is the flow should be smaller, or exhalation pressure will be not enough, and the vocal cords cannot vibrate and produce trembling sound or stop vibration due to lack of motivation.

When the sound is strong, majestic, and bold, the breath should sink to "sit" and be full. At this time, the using of breath should be intense with faster air flow speed and larger flow, so the breath should be used balanced and evenly as singing weak voice. It can't dash fiercely upwards, nor can it be pushed out by streams but to hover upward from the "back" leisurely. Otherwise, the breath will be too excessive, which will make the intonation higher and the sound stiffer. More seriously, the vocal cords will vibrate abnormally and unsteadily due to the fierce impact of breath, causing the voice shaking. If it lasts a long time, the vocal cords will have lesion caused by overload.

To sum up, we can see that the process of making sound and using breath is full of contradictions. Only by pursuing unity and balance in the contradictions can the voice be graceful.

\section{The Method of Using Breath is Diverse and Flexible}

In order to adapt to changes in the emotion of the content of songs, as well as perform the characteristics of language, style, and timbre, the method of using breath should be diverse and flexible. When singing beautifully and slow songs and / or phrases, or express subtle and missing emotions, the breath should be absorbed deeply, and then slowly "knead" outward with control and tenacity. The strength of the waist feels like knead dough or do Tai Chi, mainly soft with strength; when singing passionate or emotional indulgent songs, flow speed and flow volume of breath should be increased, so the feeling of through up and down is especially obvious and the action of the waist pushing the waist should be slightly fast and powerful. The use of breath is mainly "strong" with softness, iterating hardness and softness; when singing high-pitched folk songs and ballad with strong style or jumped tone, in order to obtain the head cavity resonance and find the height of voice, we should prepare to breath before making sound and the back waist "sits" downward with lower abdomen belly in to form confrontational force. Then we can slightly increase the breath pressure combining rigidness and softness, so that the sound wave make resonance in the head cavity, and the sound will stand upright; when singing long sentences, in order to achieve coherence and unity, we can take a breath secretly in the gap between words and sound to sing while breathing, so that obvious interruption of the breath cannot be heard.

1) Inhalation of singing: Inhalation is the preparation before singing. When inhaling, one should use both mouth and nose to inhale the air to the bottom of the lungs, so that the diaphragm goes down, the chest and abdominal cavity simultaneously expand, and waist have a feeling of expansion. When inhaling, one should pay attention to act gently and steadily, naturally and relaxed, and make moderate breath to prevent too deep or too shallow, or it is easy to cause the body to become stiff, and the sound lose elasticity and support.

2) Exhalation of singing: When air flows out of the lungs, the muscle group for inhalation slowly relaxes in a controlled manner and the diaphragm gradually lifts. The strengths of contracting of the lower abdomen and maintaining expansion of both sides of the chest form confrontation, leaving breath evenly and fluidly exhaled. When exhaling, the control over breath should be moderate, since lack of control will lead to leaking and the breath will be not enough while excessive control is likely to cause not smooth breath, resulting in stiff and dry sound. Exhaling should maintain the feeling of inhaling, and inhaling also maintain the feeling of calling. Exhaling and inhaling are the paradoxes unity of opposites. Some people summarize the unity of opposites as "singing in the way of inhaling, singing from where inhaling, thinking of inhaling in the process of singing, inhaling in the process of inhaling, and singing all the words with inhaling."

3) Taking a breath in singing: Taking a breath in singing not only is related to the exertion of sound and 
technique, but also directly affects the artistic expression of musical compositions and emotions. It is often said: "one can't sing well if he can't take a breath well." If the breath is not taken well, it may not only make the singer's voice out of control, but also affect the consistency and integrity of musical compositions and undermine the artistic conception and performance of the songs." The singers should pay attention to choose a good scavenge port when studying the songs, and in practice, strictly require them to design a good breath in advance, which cannot be moved freely. They should master the speed of taking a breath according to the mood of the music, to reasonably arrange the time of exchanging breath, better control the breath of singing and perform the intonation of musical work.

\section{THE PROBLEM IN IMPROPER USE OF BREATH}

\section{A. More Breath and Less Sound}

As the diaphragm and abdomen and psoas controlling breath is weak due to the lack of exercise, they cannot control the breath well, so the breath go out too fast with small flow volume and laryngeal vocal cords can't have time to work together, leading the airflow to encounter glottis that is not closed so that the breath misses before completely converting into sound.

\section{B. Less Breath and More Sound}

As the breath is light and exhaling volume is too small, but they cannot vibrate the vocal cords and want to sing loudly, so they pull straight throat to shout and squeeze constrainedly.

\section{High Intonation}

Some singers were unprepared for the high pitch, erroneously believing that as long as they make effort to raise the breath, they can "roar" the high pitch. Such sound that is rushed or roared straight up will make the vocal cords overloaded and lose normal vibration since breath flow is too large, the flow speed is too fast, and the pressure is not large, so that the intonation is high and the voice cannot be sustained.

\section{Swinging Sound}

Normally, the vocal cords vibrate in a horizontal and back-and-forth motion. When it is subjected to irregular or excessive gas pressure, it will hog slightly upward. Arch vocal cord need to try to restore its normal position, but the strong breath pressure rushes it into the arched shape. Therefore, the vibration of vocal cords does abnormal up and down movements in addition to the normal horizontal opening and closing. These two actions make the sound becomes fate and dull. Making sound like this in long-term, the throat muscles will become stiff and inflexible, and finally exhausted, making the sound swing.

\section{E. Low Intonation}

Because the breath is only one-way movement, blindly pushing up and out and lacking the restraint from opposite direction, the breath is often either too fast and fierce, or too lax and loose, without strength. In some cases, on the contrary, the strength of containing and maintaining is too strong and the breath is pulled too low and too heavy, so the breath cannot go up, which affects the use of resonance cavity, and the position of voice is low and white, with low pitch.

\section{CONCLUSION}

In short, the breath is the driving force of singing. The vital capacity of human is always limited, so the key is to control the breath well after inhalation, and don't waste and miss when exhaling to achieve the maximum and best sound effects with the least breath. This good and correct method of breathing can only be attained by long-lasting hard work. A perfect song not only needs a good voice, more importantly, but also need breath adjustments, so that the song can be sung perfectly and scientifically. All sound performance skills are inextricably linked to breathing. Both for a vocal lover or a vocal researcher, it's crucial to understand and master the correct breath method of vocal performance. Breath is the foundation and driving force of singing. Learning the correct breath in singing is the most important and necessary premise.

All sound performance skills are inextricably linked to breathing. Both for a vocal lover or a vocal researcher, it's necessary to understand and master the correct breath method of vocal performance. Scientific methods of breath should be trained correctly and rigorously in long term and persevered in the learning process step by step. In addition, during the actual learning process, we cannot unilaterally emphasize the breath of singing, but should combine breath and vocalization, pronouncing words and emotions well. Only by mastering and applying the breath can we find a vocal way that suits us and sing the most beautiful and pleasant voice.

\section{REFERENCES}

[1] Liang Li. On the importance of breath in singing[J] Yellow River of the Song, 2012 (16): 126-127.

[2] Dong Fang. On the use of breath in singing [J]. Journal of Chifeng College: Chinese Philosophy and Social Science Edition, 2005 (6): 55-55.

[3] Li Zanzong. On the use of breath and resonance in singing[J] Science and Technology Information, 2010 (15): 240-240. 